\title{
A eutectic salt high temperature phase change material: Thermal stability and corrosion of SS316 with respect to thermal cycling
}

\author{
Ming Liu ${ }^{\mathrm{a},{ }^{*}}$, Stuart Bell ${ }^{\mathrm{b}}$, Mercè Segarra ${ }^{\mathrm{c}}$, N.H. Steven Taya, ${ }^{\mathrm{a}, \mathrm{d}}$, Geoffrey Will ${ }^{\mathrm{b}}$, Wasim Saman ${ }^{\mathrm{a}}$, Frank \\ Bruno $^{\mathrm{a}}$ \\ a Barbara Hardy Institute, School of Engineering, University of South Australia, Mawson Lakes \\ Boulevard, Mawson Lakes, SA5095 Australia. \\ ${ }^{b}$ Energy and Process Engineering, Chemistry, Physics, Mechanical Engineering, Science and \\ Engineering Faculty, Queensland University of Technology, Brisbane 4001, QLD Australia. \\ ' DIOPMA, Dept. Materials Science and Physical Chemistry, Universitat de Barcelona, Marti i \\ Franques, 1, 08028 Barcelona, Spain. \\ d Newcastle University Singapore, 172A Ang Mo Kio Avenue 8, \#05-01, SIT Building@Nanyang \\ Polytechnic, Singapore 567739, Singapore.
}

\begin{abstract}
Thermal energy storage (TES) is a critical component in a concentrated solar power (CSP) plant since it is able to provide dispatchability and increase the capacity factor of the plant. Recently the Brayton power cycle using supercritical carbon dioxide $\left(\mathrm{s}-\mathrm{CO}_{2}\right)$ has attracted considerable attention as it allows a higher thermal to electric power conversion efficiency compared to the conventional Rankine cycle using subcritical steam. However, no commercial TES has yet been developed for integration with a s- $\mathrm{CO}_{2}$ based plant. One reason is the lack of a suitable storage material. This work explores the use of a eutectic $\mathrm{NaCl}-\mathrm{Na}_{2} \mathrm{CO}_{3}$ salt as a reliable high temperature phase change material (PCM). The PCM has been thermally cycled up to 1000 times. Its thermo-physical properties have been measured before and after it has been subjected to the thermal cycling and its corrosion behavior has been investigated. This eutectic salt shows good thermal stability without degradation after cycling 1000 times between 600 and $650{ }^{\circ} \mathrm{C}$. The corrosion rate on stainless steel 316 (SS316) increases linearly up to 350 cycles, and thereafter it stabilizes at $70 \mathrm{mg} / \mathrm{cm}^{2}$.
\end{abstract}

Key words: phase change material; thermal storage; thermal stability; dynamic gravimetric analysis; corrosion; containment material.

\section{Introduction}

Concentrated solar power (CSP) technology converts the sunlight to heat by using mirrors or lenses and a receiver, and the heat generated is used to produce electricity or process heat for industrial use. The integration of thermal energy storage (TES) solves the time mismatch between the solar energy supply and electricity/heat demand and also reduces the levelized cost of CSP-generated electricity. Sensible TES in a two-tank molten salt system has been deployed in commercial CSP plants. Latent TES using phase change material (PCM) is believed to be a cost effective alternative as it offers higher energy storage density and isothermal behavior during the phase transformation. It has been extensively investigated 
over the last few years and is currently experiencing the transition from research to industrial application via pilot-scale demonstration.

Due to the high temperature requirements for CSP systems, inorganic salts/salt eutectics and metals/metal alloys with melting points over $300^{\circ} \mathrm{C}$ are being considered as promising PCM candidates and have been reviewed [1-4]. In order to build efficient and reliable PCMTES systems, the appropriate PCMs should possess suitable phase change temperature, high latent heat of fusion, good thermal and chemical stability and acceptable corrosion on the containment material at high temperatures and after repeated thermal cycles. It is also critical to experimentally verify the thermo-physical properties of the PCM as calculated values, sometimes used in the literature show significant discrepancy $[5,6]$. In addition, limited information exists on the stability and corrosion issues of high temperature PCMs under thermal cycling.

Corrosion mechanisms in molten salt are complex and highly dependent upon impurities, temperature, alloying elements and oxidant availability. Corrosion in molten salts generally proceeds in five steps: (1) oxidant dissolving into melt, (2) oxidant transport in melt, (3) corrosion reactions at salt/metal surface, (4) oxide scale dissolution into melt, and (5) preferential dissolution of soluble products [7].The majority of high temperature corrosion tests have focused on steel in the presence of molten nitrate salt and the effect of impurities under isothermal conditions [8-10].

Sodium nitrate $\left(\mathrm{NaNO}_{3}\right)$ has been found to be a suitable PCM for direct steam generation and detailed analysis of fundamental material aspects has been carried out in [11-13]. No degradation was detected after 172 thermal cycles [12]. A 1 MWh pilot-scale TES system combining sensible and latent thermal storage with 14 tons of $\mathrm{NaNO}_{3}$ was installed and will be tested in Spain under real steam conditions [14]. Possible degradation of nitrate will lead to increasing concentration of nitrite and it will decrease the storage material's melting temperature and latent heat of fusion [15]. $\mathrm{BaCO}_{3}-47.8 \mathrm{Na}_{2} \mathrm{CO}_{3}$ (wt. \%) has shown good thermal stability after 36 cycles [16]. After evaluating six eutectic salts by thermal cycling up to 100 cycles, $\mathrm{Li}_{2} \mathrm{CO}_{3}-35 \mathrm{~K}_{2} \mathrm{CO}_{3}-33 \mathrm{Na}_{2} \mathrm{CO}_{3}$ (wt. \%) and $\mathrm{MgCl}_{2}-48 \mathrm{NaCl}$ (wt. \%) were identified as promising high temperature PCMs [6]. Al-34\%Mg-6\%Zn (wt.\%) alloy has a good thermal reliability after 1000 thermal cycles and SS304L can be considered as a containment material [17]. An X-750 alloy container was dissolved by molten aluminum under repeated thermal cycles in a vacuum condition [18].

A eutectic salt composed of $\mathrm{NaCl}-\mathrm{Na}_{2} \mathrm{CO}_{3}$ was explored as a high temperature $\mathrm{PCM}$ by Jiang et al. [19]. The PCM showed no decomposition under $\mathrm{CO}_{2}$ atmosphere and little decomposition ( $0.15 \%$ weight loss) under $\mathrm{N}_{2}$ atmosphere up to $700{ }^{\circ} \mathrm{C}$. Also, it showed good thermal properties and stability after 100 thermal cycles. This preliminary test proved its potential as a PCM. However, the corrosion issues of this PCM have not been investigated. Previous research on corrosion of molten chloride salt showed that lower nobility transition metals such as chromium and iron tend to be more susceptible to corrosion and dissolution 
than higher nobility metals such as nickel [20]. Passive oxide scale on the surface of a metal in a chloride salt has been found to slow ion dissolution from the metal, and its stability can be improved by the introduction of carbonate ions [21]. However, the formation of passive oxide films is difficult and depends upon specific conditions which may not be easily maintained, causing the oxide to be removed by fluxing [22].

This paper presents work on the long-term thermal stability of eutectic $\mathrm{NaCl}-\mathrm{Na}_{2} \mathrm{CO}_{3}$ by measuring the thermo-physical properties of the PCM after repeated thermal cycles of heating/cooling up to 1000 times. The corrosion behavior of a common containment material (SS316) in the presence of eutectic $\mathrm{NaCl}-\mathrm{Na}_{2} \mathrm{CO}_{3}$ salt with respect to thermal cycling was also explored. The mass-loss corrosion rate of steel coupons with increasing number of cycles was determined by the dynamic gravimetric analysis. The microstructure of the corrosion product was evaluated by examining the cross sections of the metal coupons.

\section{Experimental Methods}

\subsection{Sample preparation}

The sodium chloride $(\mathrm{NaCl})$ and sodium carbonate $\left(\mathrm{Na}_{2} \mathrm{CO}_{3}\right)$ were supplied by ACE Chemicals (Australia). They were technical grade with a purity of $\min .99 .4 \%$ and $\min .99 .2 \%$, respectively. The major impurities in $\mathrm{NaCl}$ are magnesium (mix. $0.05 \%$ ), calcium (mix. $0.1 \%$ ) and sulphate (max. $0.25 \%$ ). The major impurities in $\mathrm{Na}_{2} \mathrm{CO}_{3}$ are $\mathrm{NaCl}(\max .0 .5 \%), \mathrm{Fe}_{2} \mathrm{O}_{3}$ ( $\max .0 .005 \%), \mathrm{CaO}(\max .0 .007 \%)$ and $\mathrm{MgO}$ (max. $0.006 \%$ ). The salts were not further purified since the process is complicated and will increase the cost for industrial applications. The single salts were placed in a furnace at $120^{\circ} \mathrm{C}$ for 24 hours to exclude moisture. The $\mathrm{PCM}$ was prepared by mixing $\mathrm{NaCl}$ and $\mathrm{Na}_{2} \mathrm{CO}_{3}$ in the weight proportion of 40.55 and 59.45 and the mixture was melted at $650{ }^{\circ} \mathrm{C}$ in a porcelain crucible and maintained for 2 hours at atmospheric pressure in air. Afterwards, the salt was pulverized to powder using a pestle and mortar and stored in sealed containers.

Ten SS316 coupons with dimensions of approx. $20 \mathrm{~mm} \times 10 \mathrm{~mm} \times 1.5 \mathrm{~mm}$ were cut from a sheet of stainless steel. The nominal composition of the SS316 is presented in Table 1 . The maximum service temperatures of SS316, which is the highest temperature at which it can be used for an extended period without significant problems (e.g. oxidation and decrease of mechanical properties), are $870^{\circ} \mathrm{C}$ and $925^{\circ} \mathrm{C}$ for intermittent and continuous service in air, respectively [23]. The coupons were progressively polished using $\mathrm{SiC}$ abrasive papers of 400, 800 and 1200 grit, cleaned with acetone in an ultrasonic bath, further cleaned in deionized water and weighed. All the coupons' weights and dimensions were recorded.

Table 1. Nominal elemental composition of stainless steel 316.

\begin{tabular}{|l|l|l|l|l|l|l|l|l|l|}
\hline Element & $\mathrm{C}$ & $\mathrm{Cr}$ & $\mathrm{Mo}$ & $\mathrm{Ni}$ & $\mathrm{Si}(\max )$. & $\mathrm{Mn}$ (max.) & $\mathrm{P}$ (max.) & $\mathrm{S}$ (max.) & Fe \\
\hline wt. \% & 0.07 & $17-18.5$ & $2-2.5$ & $10.5-13.5$ & 1.0 & 2.0 & 0.045 & 0.030 & Balance \\
\hline
\end{tabular}


The PCM samples (each approx. $50 \mathrm{~g}$ ) were placed into alumina crucibles as this material has shown corrosion resistance to the investigated salt system. The SS coupons were inserted into and fully submerged in PCM samples. Type $\mathrm{K}$ omega ${ }^{\mathrm{TM}}$ thermocouples with an accuracy of $\pm 0.75 \%$, were used. They were covered with alumina sheaths to protect the thermocouple from the corrosion. The sheathed thermocouples were inserted into one PCM sample to record the sample temperature. Then, all the samples were covered by lids and placed in a furnace. The temperature of the furnace was programed to cycle between $600{ }^{\circ} \mathrm{C}$ and $650^{\circ} \mathrm{C}$, including a heating process to $650^{\circ} \mathrm{C}$ with a heating rate of $10 \mathrm{~K} / \mathrm{min}$, an isothermal process at $650^{\circ} \mathrm{C}$ for $2 \mathrm{hrs}$, a cooling process to $600^{\circ} \mathrm{C}$ with natural cooling of furnace and an isothermal process at $600{ }^{\circ} \mathrm{C}$ for $2 \mathrm{hrs}$. The temperatures inside the PCM sample and the furnace were recorded every 10 seconds by using a data acquisition system.

One crucible with salt only as the sample was removed from the furnace after 200, 500, 650 and 1000 thermal cycles for thermo-physical property characterization, respectively. Two crucibles with salt and SS coupons were removed from the furnace after 50, 100, 150, 350 and 500 cycles, respectively. One coupon was prepared for dynamic gravimetric analysis to determine the corrosion rate and the other for microstructural analysis. The SS coupons were preliminarily cleaned by washing off the salt using warm water and followed by deionized water.

\subsection{PCM characterization (differential scanning calorimetry)}

A high temperature differential scanning calorimeter (DSC 404 F1 Pegasus ${ }^{\circledR}$, Netzsch) was used to measure the phase change temperature and phase change enthalpy of the fresh and cycled PCM samples. The samples were pulverized to powder after removal from the furnace and dried in a furnace at $120^{\circ} \mathrm{C}$ for 2 hours before the measurement. Six specimens ( $15 \pm 1 \mathrm{mg}$ each) were taken from each sample and the average values were obtained. The eutectic $\mathrm{NaCl}-\mathrm{Na}_{2} \mathrm{CO}_{3}$ was shown to decompose at temperatures beyond $638^{\circ} \mathrm{C}$ under air atmosphere [24]. Therefore, the specimen was obtained from at least $10 \mathrm{~mm}$ below the top surface. In the real storage tank, a $\mathrm{CO}_{2}$ atmosphere should be applied, under which the salt remains stable to $700^{\circ} \mathrm{C}$ [19]. The specimen was loaded into the $85 \mu \mathrm{l} \mathrm{Pt} / \mathrm{Rh}$ crucible with an alumina liner and it was subject to two heating and cooling cycles with a heating/cooling rate of $10 \mathrm{~K} / \mathrm{min}$ in nitrogen atmosphere.

The software Proteus ${ }^{\circledast}$ from Netzsch was used to evaluate the heat flux signals. The baseline onset temperature during heating and cooling was regarded as the melting and solidification temperature, respectively. The phase change enthalpy was estimated by the integration of the heat flux under phase transformation. 


\subsection{Containment material characterization}

\subsubsection{Dynamic Gravimetric Analysis (DGA)}

The effect of corrosion was determined by measuring the amount of corrosion products formed on the surface of the SS316 sample, by using the dynamic gravimetric analysis (DGA) [8]. The traditional methods proposed by the ASTM Standard G1-03 [25] requires intensive sample manipulation, while the DGA technique reduces human handling when determining the corrosion rate, and improves the accuracy of results.

Initially, the residual salts adhered to the SS surface were removed by submerging the SS coupons into $10 \% \mathrm{v} / \mathrm{v}$ sulphuric acid solution for 15 mins. Sulphuric acid at low concentrations also makes the oxide layer become less compact and thus facilitates the oxide descaling process without removing the corrosion layer itself. Following this procedure [8], the coupon was then hung from an analytical balance (Ohaus Explorer) with an accuracy of $\pm 0.1 \mathrm{mg}$ and submerged in the cleaning solution, allowing the dissolution of the formed scales. The balance was connected to a computer (software RealTerm: Serial Capture Programme 2.0.0.43) which recorded the weight of the coupon every second, providing a real-time weight loss of the descaling process.

The cleaning solution used in this work was defined in the ASTM Standard G1-03 and it consists of $100 \mathrm{ml} 69 \% \mathrm{v} / \mathrm{v} \mathrm{HNO} 3,20 \mathrm{ml} 48 \% \mathrm{v} / \mathrm{v} \mathrm{HF}$ and distilled water up to $1 \mathrm{~L}$ [25]. Each studied SS coupon was immersed in the solution for 50 minutes following the DGA procedure. This duration was experimentally determined to ensure that the oxide layer was completely removed. Finally, the samples were cleaned with distilled water, dried with absorbent paper, and weighed.

From the data captured by the software, a curve of weight loss versus time can be depicted. This curve depends on the amount of oxide formed on the surface of the SS coupon, and therefore, it can be related to the corrosion resistance. From the curve, the thickness $x_{M}$ of corroded steel can be calculated by Eq. (1)

$x_{M}=\frac{w_{i}^{a i r}-\left[w_{f}^{a i r}+\left(w_{o x}^{c S}-w_{f}^{c S}\right) \times B\right]}{S \rho_{M}}$

where $w_{i}^{\text {air }}$ and $w_{f}^{\text {air }}$ are the initial and final weights of the SS coupon in air before and after the DGA test, $w_{o x}^{c S}$ is the weight of the SS coupon inside the cleaning solution when all the oxide layer has been removed (the point on the graph in which the slope changes [8]), $w_{f}^{c S}$ is the final weight of the SS coupon inside the cleaning solution, $S$ is the surface area, and $\rho_{M}$ is the density of the steel $\left(7.85 \mathrm{~g} / \mathrm{cm}^{3}\right) . B$ is the experimental buoyancy of cleaning solution, which can be determined by the ratio of weight loss in air $\left(\Delta w^{\text {air }}\right)$ and weight loss inside the cleaning solution $\left(\Delta w^{c S}\right)$ as shown in Eq. (2).

$B=\frac{\Delta w^{\text {air }}}{\Delta w^{c s}}=\frac{w_{f}^{\text {air }}-w_{i}^{\text {air }}}{w_{f}^{c s}-w_{i}^{c s}}$

where $w_{i}^{c S}$ is the initial weight of the SS coupon inside the cleaning solution before the DGA test. 
Although the plates were cut as precisely as possible, they were not identical in weight and surface area. Thus for comparative purposes, the weight loss per unit area, $w_{\text {loss }}\left(\mathrm{mg} / \mathrm{cm}^{2}\right)$, is calculated by multiplying the thickness of corroded steel $\left(x_{M}\right)$ by its density $\left(\rho_{M}\right)$.

On the other hand, the thickness of the oxide layer $\left(x_{\text {oxide }}\right)$ can also be calculated from the thickness of corroded steel, taking into account the stoichiometry of the iron oxide (for example, $\left.\mathrm{Fe}_{\mathrm{x}} \mathrm{O}_{\mathrm{y}}\right)$, its molecular weight $\left(M_{\text {oxide }}\right)$, and its density $\left(\rho_{\text {oxide }}\right)$, by Eq. (3).

$x_{\text {oxide }}=\frac{x_{M} \rho_{M} M_{\text {oxide }}}{n_{F e} \rho_{\text {oxide }} A_{F e}}$

$n_{\mathrm{Fe}}$ being the number of iron atoms per mole of oxide, and $A_{F e}$ the atomic weight of iron.

\subsubsection{Microstructural characterization}

Microstructural characterization was undertaken using a Zeiss Sigma Field Emission Scanning Electron Microscope (SEM) and an Oxford XMax 50 Silicon Drift (SDD) EDS detector provided Energy Dispersive X-ray Spectroscopy (EDS) mapping. Samples were cross sectioned, mounted in resin and polished via the following procedure:

1. SiC Foil 320 grit, with water lubricant for 1 minute at $30 \mathrm{~N}$ per sample.

2. MD Largo, with DiaPro Allegro/Largo lubricant/suspension for 3 minutes at $20 \mathrm{~N}$ per sample.

3. MD Mol, with DiaPro Mol B3 lubricant/suspension for 3 minutes at $20 \mathrm{~N}$ per sample.

4. MD Nap, with DiaPro Nap B1 lubricant/suspension for 2 minutes at $20 \mathrm{~N}$ per sample.

5. MD Chem with OP-U colloidal silica lubricant/suspension for 1 minute at $10 \mathrm{~N}$ per sample.

Both surface and cross-section areas were examined.

\section{Results and discussion}

\subsection{Thermal stability of PCM}

The onset melting and solidification temperatures and phase change enthalpy was evaluated for six specimens for each fresh and cycled PCM sample. The results obtained from the second freezing process were not included as a result of the salt creeping after two melting processes. The experimental difficulty with molten salt creeping has been reported previously $[6,13,26]$. A thin film of molten salt forms on the surface, which will wet the crucible material and creep up the crucible wall and even out of the crucible. The maximum and minimum values for each specimen were excluded from the calculation and the average value and its standard deviation was calculated based on the remaining four values. The average phase change temperature, sub-cooling and enthalpy during melting and solidification, together with their standard deviations, at various numbers of thermal cycles are listed in Table 2. The low standard deviation confirms that the four value points are close to the average value and the error ( $\sigma$, standard deviation divided by average value) for all the measurement is below $3.64 \%$, which is within the measurement error of the DSC. 
Table 2. Phase change temperature and enthalpy of PCM samples measured by DSC.

\begin{tabular}{lcccccccc}
\hline $\begin{array}{l}\text { Cycle } \\
\text { no. }\end{array}$ & \multicolumn{2}{c}{$1^{\text {st }}$ Melting Process } & \multicolumn{2}{c}{$1^{\text {st }}$ Solidification Process } & $2^{\text {nd }}$ Melting Process & $\begin{array}{c}\text { Sub- } \\
\text { cooling } \\
(\mathrm{K})\end{array}$ & $\begin{array}{c}\text { Storage } \\
\text { efficiency } \\
(\%)\end{array}$ \\
\hline Fresh & $642.6 \pm 0.7$ & $322.8 \pm 3.9$ & $633.6 \pm 0.2$ & $308.8 \pm 1.1$ & $635.0 \pm 0.7$ & $311.6 \pm 1.0$ & 1.4 & 99.1 \\
200 & $642.1 \pm 3.7$ & $323.4 \pm 4.1$ & $631.9 \pm 0.6$ & $305.4 \pm 1.1$ & $634.9 \pm 1.4$ & $313.6 \pm 4.6$ & 3.0 & 97.4 \\
500 & $636.2 \pm 1.1$ & $324.4 \pm 3.9$ & $632.0 \pm 0.1$ & $310.7 \pm 4.8$ & $632.6 \pm 0.3$ & $313.3 \pm 3.4$ & 0.6 & 99.2 \\
650 & $638.1 \pm 3.2$ & $320.3 \pm 11.7$ & $631.9 \pm 0.7$ & $305.7 \pm 2.4$ & $633.9 \pm 1.4$ & $311.1 \pm 2.1$ & 2.0 & 98.3 \\
1000 & $639.5 \pm 3.5$ & $319.4 \pm 8.8$ & $632.2 \pm 0.5$ & $304.6 \pm 6.5$ & $634.1 \pm 1.1$ & $310.2 \pm 3.7$ & 1.9 & 98.2 \\
\hline$\sigma$ & $0.58 \%$ & $3.64 \%$ & $0.10 \%$ & $1.53 \%$ & $0.22 \%$ & $1.48 \%$ & & \\
\hline
\end{tabular}

Tonset: onset temperature; $\Delta \mathrm{H}_{\mathrm{m}}$ : phase change enthalpy.

240 Generally, the melting temperature, phase change enthalpy and their variations amongst specimens in the first melting process were higher than those in the succeeding solidification and the melting processes. The difference is between $3.7^{\circ} \mathrm{C}$ and $7.7^{\circ} \mathrm{C}$ for melting temperature and between $9.2 \mathrm{~J} / \mathrm{g}$ and $11.2 \mathrm{~J} / \mathrm{g}$ for the phase change enthalpy, respectively. A similar trend was observed by Shukla et al. [27] and Liu and Chung [28]. This discrepancy is likely due to the high thermal contact resistance between the salt and the crucible pan in the initial melt. The contact is improved in the second melt as space is eliminated between the salt and pan due to the initial melt. The phase change temperature during the second melting process was regarded as the melting temperature of the sample as discussed below.

The melting temperature and the phase change enthalpy measured in this work along with their theoretical values calculated using FactSage 6.4 and the data reported in previous literature are listed in Table 3. It shows that the differences of melting temperature between the theoretical and measured values are small, the maximum difference being $5 \mathrm{~K}$ $(0.8 \%)$. The phase change enthalpy measured in this work and another study [19] is 16.73 $\mathrm{J} / \mathrm{g}$ (5.7 \%) higher and $11.6 \mathrm{~J} / \mathrm{g}$ (3.9\%) lower than the calculated value in FactSage 6.4, respectively, which is acceptable as the discrepancy. However, values obtained in [29] are around two thirds less than the other three values. This could be due to the impurities in the salt, salt creeping, salt decomposition or improper calibration of the DSC as insufficient information is given in [29].

Table 3. A comparison between the melting temperature and phase change enthalpy of eutectic $\mathrm{NaCl}-\mathrm{Na}_{2} \mathrm{CO}_{3}$ from the present work and other sources.

\begin{tabular}{lll}
\hline Source & Melting temperature $\left({ }^{\circ} \mathrm{C}\right)$ & Phase change enthalpy $(\mathrm{J} / \mathrm{g})$ \\
\hline FactSage $6.4[19]$ & 632.0 & 294.9 \\
\hline Jiang et al. [19] & 637.0 & 283.3 \\
\hline Ye et al. [29] & 635.85 & 101.12 \\
\hline this work & 635.0 & 311.6 \\
\hline
\end{tabular}


271

and exothermic peak (during solidification), which indicates this PCM has good energy storage and release characteristics. The melting temperature is between $632.6^{\circ} \mathrm{C}$ and $635.0^{\circ} \mathrm{C}$ and phase change enthalpy is between $310.2 \mathrm{~J} / \mathrm{g}$ and $313.6 \mathrm{~J} / \mathrm{g}$. As seen in Table 2 and Figure 1 , the change in phase change temperature and enthalpy with increasing number of cycles is not significant, indicating its good thermal stability over 1000 thermal cycles.
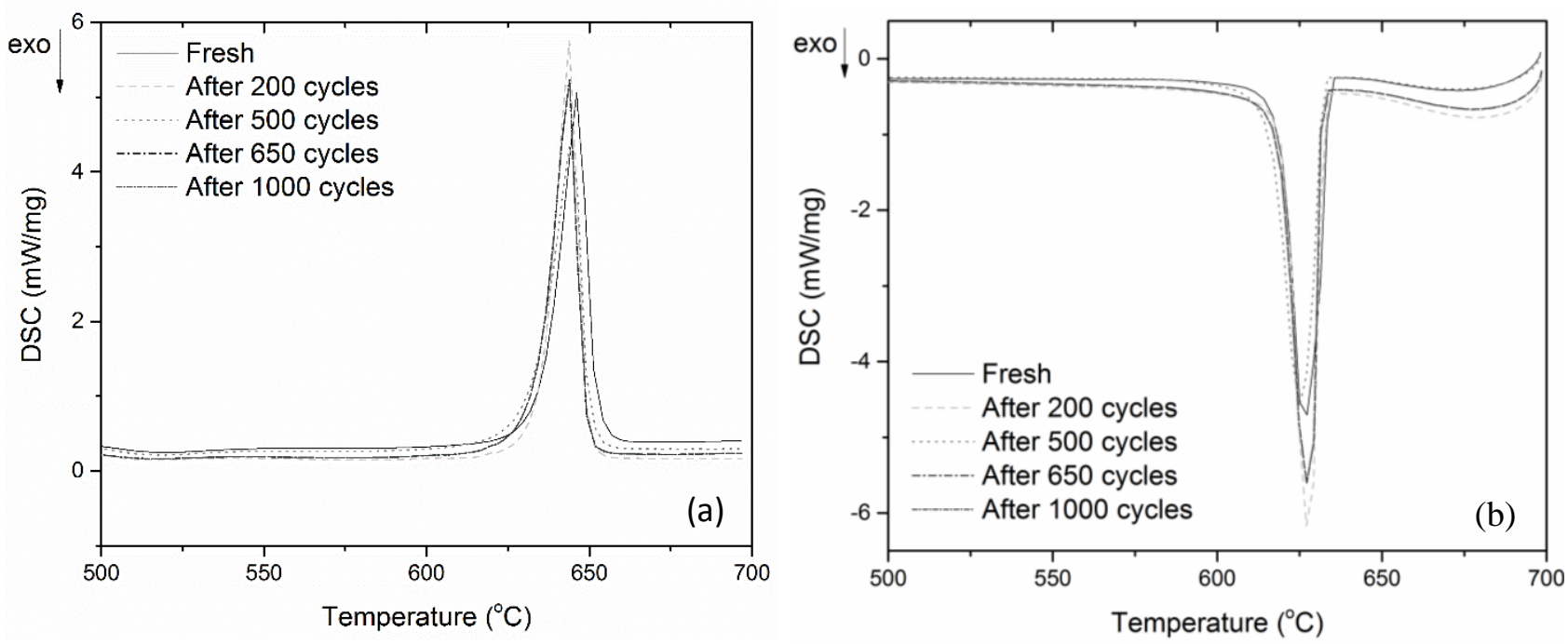

Figure 1. DSC curves of eutectic NaCl- $\mathrm{Na}_{2} \mathrm{CO}_{3}$ after various numbers of thermal cycles: (a) melting process and (b) freezing process.

The solidification temperatures of the PCM were determined as $631.9-633.6^{\circ} \mathrm{C}$ over cycling, which is $0.6-3.0^{\circ} \mathrm{C}$ lower than its melting temperature as a result of subcooling. Due to the subcooling phenomenon, the phase change enthalpy obtained from the solidification process is lower than obtained from the melting process. The energy storage efficiency is calculated by dividing the phase change enthalpy during the solidification process by the phase change enthalpy during the melting process. The minimum storage efficiency is $97.4 \%$ and it means that $97.4 \%$ of the stored energy can be recovered during the solidification, indicating a good energy recovery of the PCM.

\subsection{Mass-loss corrosion rate}

Corrosion rate measurements as a function of the number of cycles, for the studied salt mixture are shown in Figure 2. The assessment of the corrosion data is based on purely uniform corrosion. As can be observed from Figure 2, initially, the mass loss increases with the number of cycles, and the increase is nearly linear. Then it reaches around $70 \mathrm{mg} / \mathrm{cm}^{2}$ until 350 cycles. Further cycles up to 500 do not influence the corrosion rate, thus indicating that a passivation layer could be formed that prevents further corrosion. 


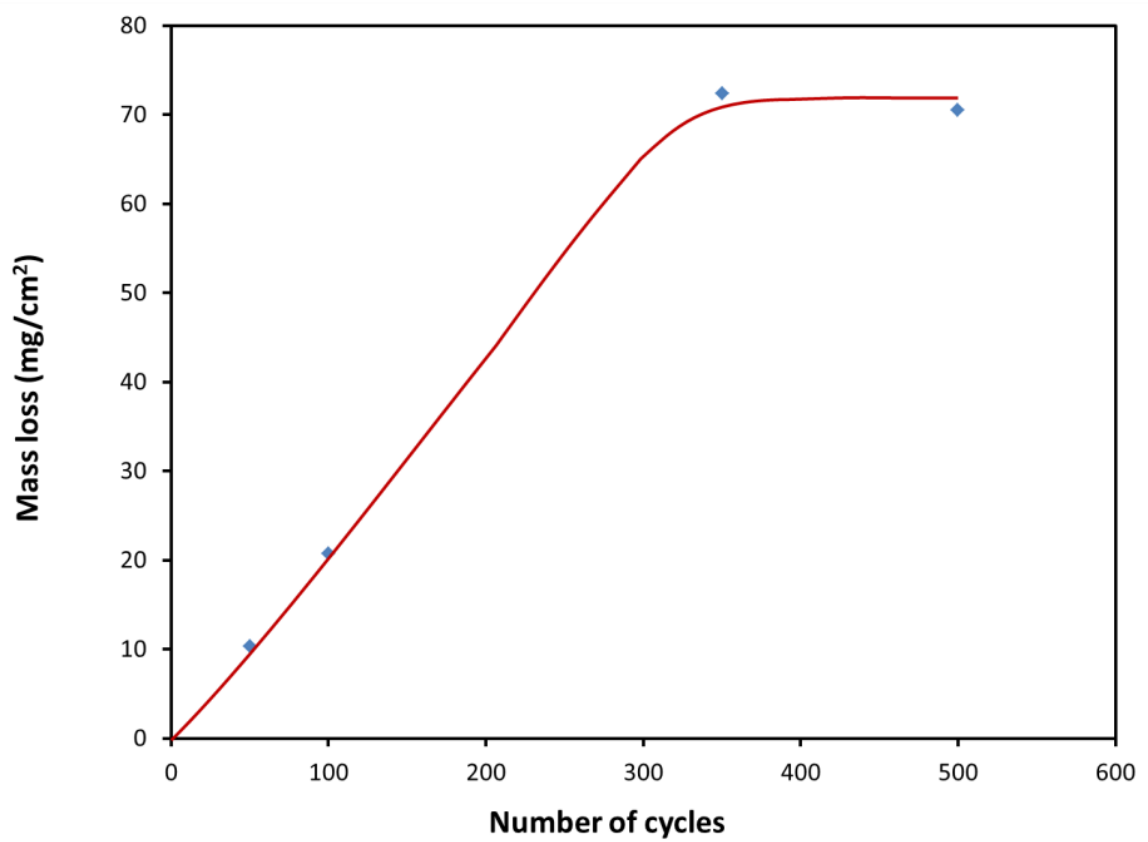

291

Figure 2. Mass loss as a function of the number of cycles, obtained from the DGA methodology.

Using Eq. (3) the total thicknesses of oxide layer can be determined with this technique. If we consider the oxide formed as pure and compact iron oxide $\left(\mathrm{Fe}_{2} \mathrm{O}_{3}\right.$, with a theoretical density of $5.26 \mathrm{~g} / \mathrm{cm}^{3}$ ), the calculated thicknesses of the oxide layer become: $28,56,197$, and $192 \mu \mathrm{m}$, for 50,100, 350, and 500 cycles, respectively. Unfortunately, as will be later explained, EDS analysis of the corroded surfaces indicate that the composition of scales are far from being pure and compact iron oxide and thus these values should be considered as an order of magnitude.

\subsection{Microstructure of containment material}

A typical SEM image with EDS analysis on the surface of the submerged coupon that underwent 100 cycles is presented in Figure 3. There are four distinct corrosion products as shown in Figure 3: sodium iron oxide (dark region in lower left), iron oxide in lower right, iron nickel chromium oxide on the top and base metal (bright central section).

Backscatter SEM images with EDS insets of cross-sectioned samples are shown in Error! Reference source not found.a-d. These were undertaken for the SS coupons that have been subject to 50, 100, 350 and 500 thermal cycles submerged in the salt. The corrosion products were studied and the thickness of the products was measured and summarized in Table 4. 
The 50-cycle sample shows a two layered corrosion film, a thicker outer layer of primarily iron oxide and a thinner inner layer which includes chromium and nickel. Three to four layers exist in the 100-cycle sample, an inner iron chromium nickel oxide of approximately $10 \mu \mathrm{m}$ thickness, an intermediate iron oxide layer also $10 \mu \mathrm{m}$ thick and a very thin (approximately $5 \mu \mathrm{m}$ ) sodium iron oxide layer. There is also an outer iron chromium nickel oxide layer present in some sections.

\section{Cycles Surface}

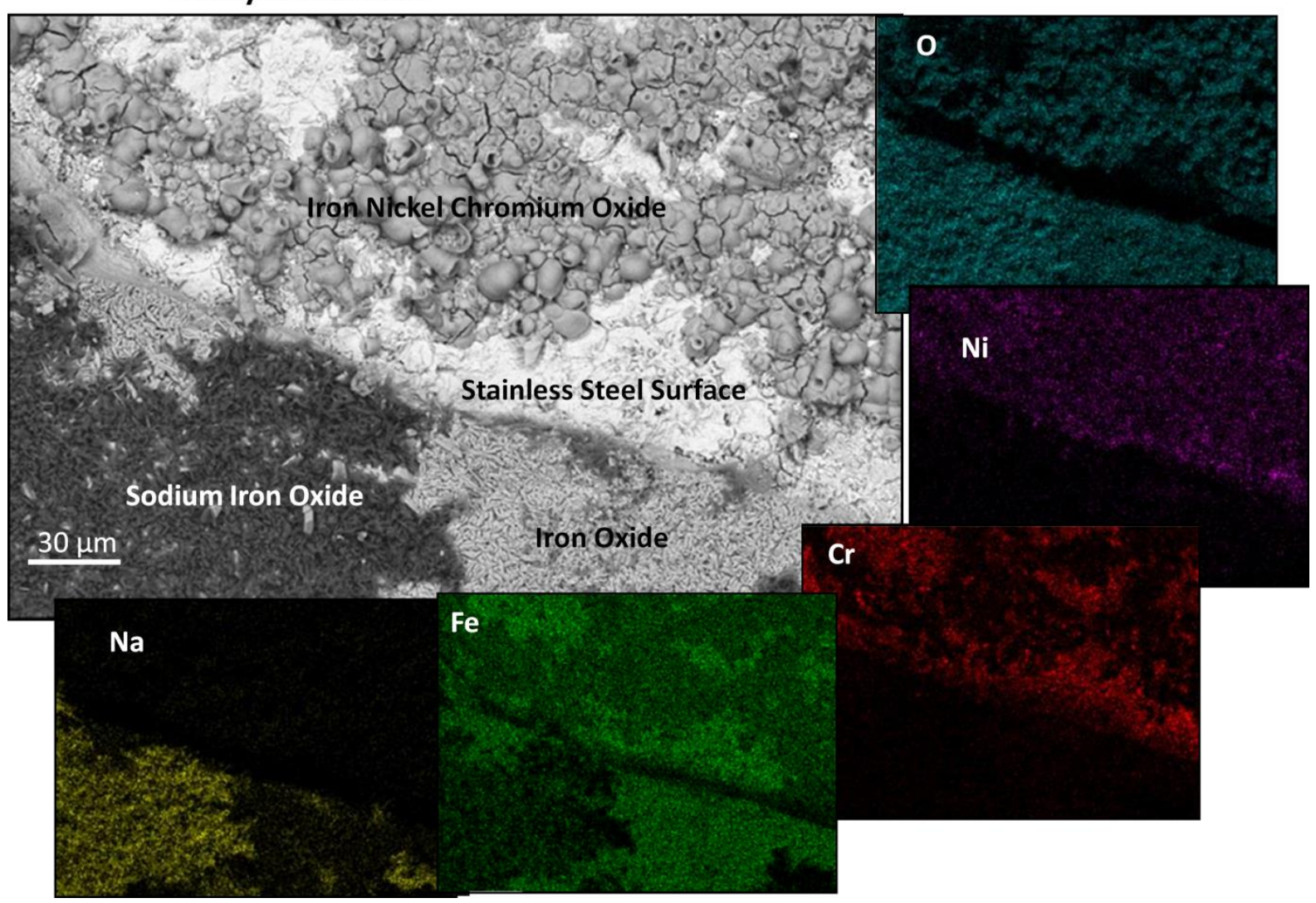

Figure 3. Electron Backscatter image with EDX plots and compositions for 4 different products.

Table 4. Cross-section corrosion layer thickness with number of thermal cycles.

\begin{tabular}{c|c|c|c|c|c}
\hline Sample & $\begin{array}{c}\text { Total oxide } \\
\text { layer thickness } \\
(\boldsymbol{\mu m})\end{array}$ & $\begin{array}{c}\text { Thickness of iron } \\
\text { nickel chromium } \\
\text { oxide, outer }(\boldsymbol{\mu m})\end{array}$ & $\begin{array}{c}\text { Thickness of } \\
\text { sodium iron } \\
\text { oxide }(\boldsymbol{\mu m})\end{array}$ & $\begin{array}{c}\text { Thickness } \\
\text { of iron } \\
\text { oxide }(\boldsymbol{\mu m})\end{array}$ & $\begin{array}{c}\text { Thickness of iron } \\
\text { nickel chromium } \\
\text { oxide, inner }(\boldsymbol{\mu m})\end{array}$ \\
\hline 50 cycles & $25-30$ & - & - & $15-20$ & $10-15$ \\
100 cycles & $35-45$ & $\sim 10$ & $\sim 5$ & $\sim 10$ & $10-15$ \\
350 cycle & $90-110$ & - & $\sim 20$ & $25-30$ & $50-60$ \\
500 cycles & $80-85$ & - & $\sim 20$ & $5-10$ & $50-60$ \\
\hline
\end{tabular}

Three distinct layers are evident in the well-developed corrosion layers of the samples subject to 350 and 500 cycles. A sodium iron oxide layer with a thickness of approximately $20 \mu \mathrm{m}$ is present at the salt/corrosion interface. An intermediate layer of primarily iron oxide $25-30 \mu \mathrm{m}$ thick in the 350 cycles sample is reduced to 5-10 $\mu \mathrm{m}$ in the 500 -cycle 
sample. The inner layer in both samples is a 50-60 $\mu \mathrm{m}$ thick iron chromium nickel oxide in contact with the bulk metal.

The corrosion layer in the 50-cycles sample has not yet formed the sodium iron oxide outer layer which appears to be developing in the 100 cycles sample and it is significant in the longer term test samples. It is likely that the iron oxide layer is formed when the chromium oxide present on the surface is dissolved by the salt. Optical Emission Spectroscopy (OES) tests performed on the salts after testing reveals the presence of both iron and chromium. The higher chromium and nickel concentration in the oxide at the metal surface is likely due to the growth of the oxide layer into the bulk metal and the outer iron oxide layer inhibiting chromium migration into the salt. When the iron oxide layer gains enough thickness, it prevents chromium migration into the salt. This is evident in the 350- and 500-cycle samples with thick iron chromium nickel layers. The nickel in this layer forms a metal lattice as nickel is less reactive to oxidization than iron and chromium. Both the presence of an alkali metal anion/iron oxide outer layer, and chromium depletion from bulk metal and oxide layers have been identified previously in the literature [7, 30, 31].

Finally, it is noted that the 500-cycle sample has a reduced total oxide layer thickness compared with the 350-cycle sample. This reduction appears to be related to the intermediate iron oxide layer which has shrunk considerably. The sodium iron oxide layer has been previously identified as non-protective under similar conditions [32]. This layer is likely to be removed during cycling, but retains its thickness as it progressively transforms the iron oxide layer.

a)

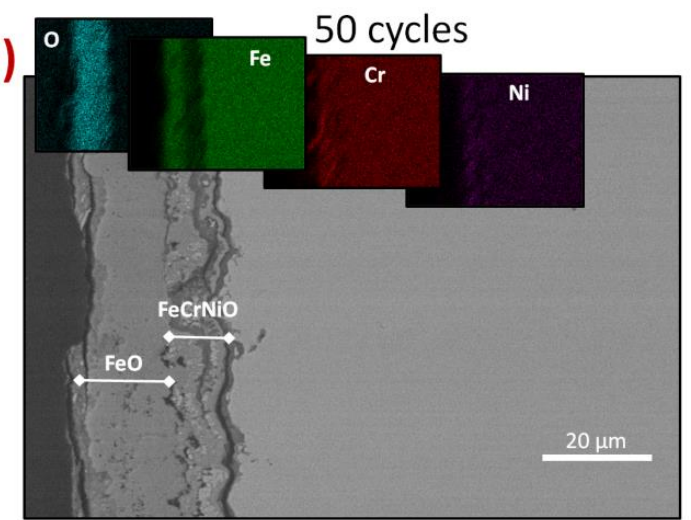

c)

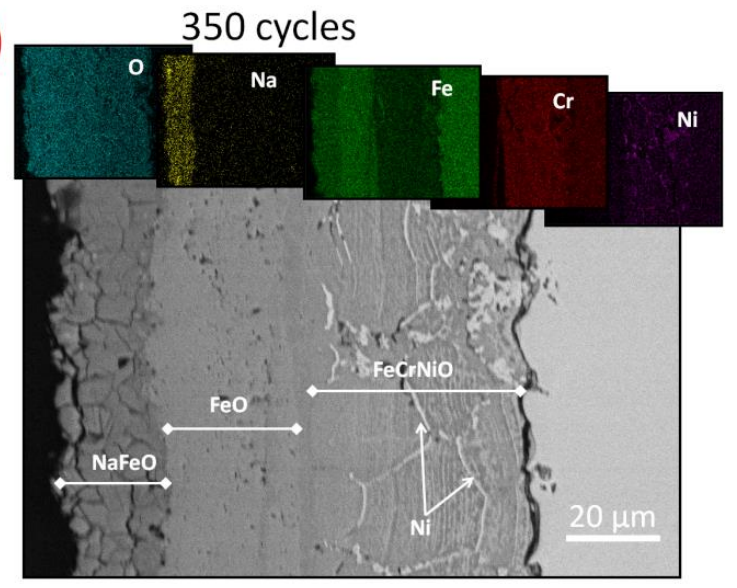

b)
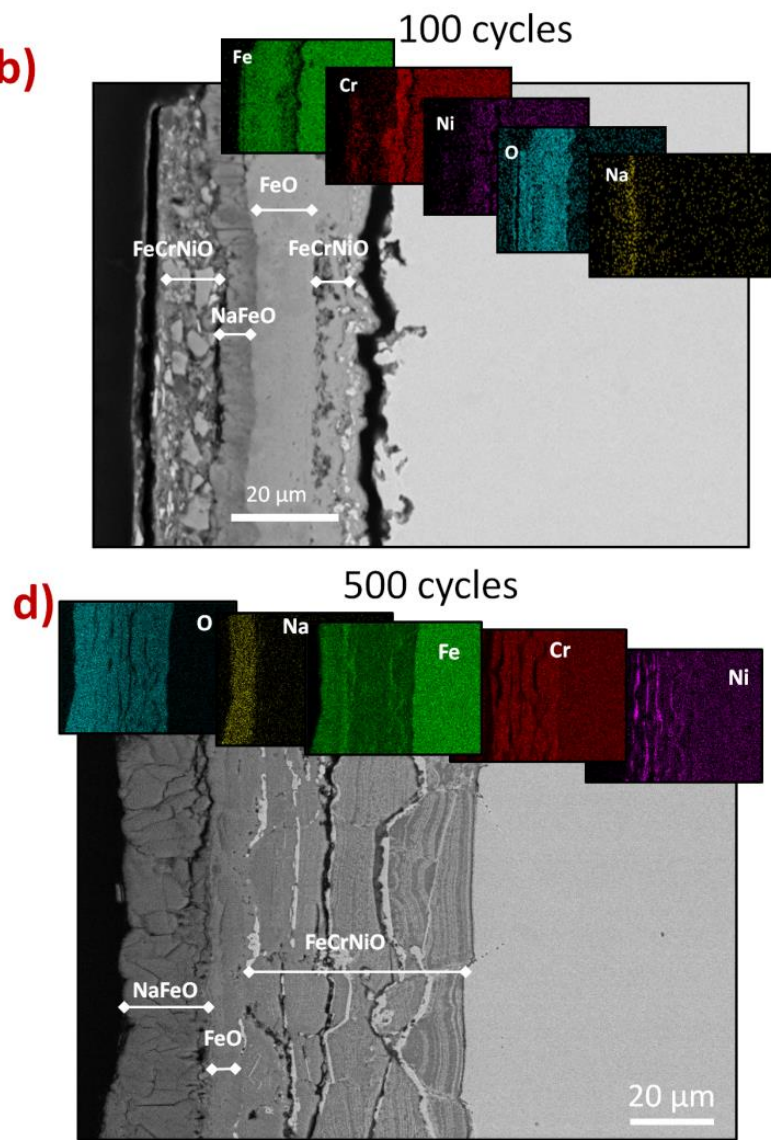
Figure 4. Electron Backscatter and EDX images of the composition of a) 50 cycles, b) 100 cycles, c) 350 cycles and d) 500 cycles corrosion layers - sodium iron oxide, iron oxide and iron, chromium, nickel oxide (labels represent the presence of indicated elements).

\section{Conclusion}

A long-term stability test has been conducted on a eutectic $\mathrm{NaCl}-\mathrm{Na}_{2} \mathrm{CO}_{3} \mathrm{PCM}$. The measured thermo-physical properties of this PCM did not vary significantly over 1000 thermal cycles. This verifies the potential of this material as a candidate PCM due to its ability to maintain its thermal energy storage capacity.

The oxide film remaining on the surface of the test coupons grew to a thickness of $90-$ $110 \mu \mathrm{m}$ and developed from a primarily iron oxide layer into three distinct layers, an inner iron chromium nickel oxide layer at the metal surface, an intermediate iron oxide layer and a sodium iron oxide layer at the salt interface. This oxide film appears to have prevented significant chromium depletion and damage to the samples submerged under that salt.

During the experiments, some of the formed scales are dissolved or fall into the melted salts. Therefore, the thickness of the outer scale layer determined by SEM could not include them. From DGA, the corrosion rate can be calculated more precisely as it takes into account those scales lost during experiments and handling. For this reason, results obtained for thicknesses are greater than those observed by SEM. The mass loss increases linearly with the number of cycles, reaching around $70 \mathrm{mg} / \mathrm{cm}^{2}$ at 350 cycles. From SEM results it can be observed that the first oxide layer on the steel (mainly formed by chromium, iron and nickel oxides), has approximately the same thickness at 350 and 500 cycles, which could indicate the stable passivation layer formation.

To identify the full potential use of SS316 as the containment material for the developed PCM, longer term thermal cycling testing has to be performed to: (1) verify the no/slow growth of this passivation layer after 350 cycles and (2) examine the stability of this passivation layer after 500 cycles.

\section{Acknowledgements}

This research was performed as part of the Australian Solar Thermal Research Initiative (ASTRI), a project supported by the Australian Government, through the Australian Renewable Energy Agency (ARENA). The authors also acknowledge the South Australian Department of State Development who have funded this research through the Premier's Research Industry Fund - International Research Grant Program (IRGP 33). Authors also wish to thank the European Union's Seventh Framework Programme (FP7/2007-2013) that under the Grant Agreement PIRSES-GA-2013-610692 (INNOSTORAGE) has facilitated the development of this research activity. This work has also been partially funded by the Spanish government (ENE2015-64117-C5-2-R (MINECO/FEDER)).

\section{References}


[1] M. Liu, W. Saman, F. Bruno, Review on storage materials and thermal performance enhancement techniques for high temperature phase change thermal storage systems, Renewable and Sustainable Energy Reviews, 16 (2012) 2118-2132. [2] M. Liu, N.H. Steven Tay, S. Bell, M. Belusko, R. Jacob, G. Will, W. Saman, F. Bruno, Review on concentrating solar power plants and new developments in high temperature thermal energy storage technologies, Renewable and Sustainable Energy Reviews, 53 (2016) 1411-1432. Renewable and Sustainable Energy Reviews, 14 (2010) 955-970.

[4] B. Zalba, J.M. Marín, L.F. Cabeza, H. Mehling, Review on thermal energy storage with phase change: materials, heat transfer analysis and applications, Applied Thermal Engineering, 23 (2003) 251-283.

[5] J. Gomez, G.C. Glatzmaier, A. Starace, C. Turchi, J. Ortega, High temperature phase change materials for thermal energy storage applications, in: SolarPACES, Granada, Spain, 2011.

[6] M. Liu, J.C. Gomez, C.S. Turchi, N.H.S. Tay, W. Saman, F. Bruno, Determination of thermo-physical properties and stability testing of high-temperature phase-change materials for CSP applications, Solar Energy Materials and Solar Cells, 139 (2015) 81-87.

[7] A.M. Kruizenga, Corrosion mechanisms in chloride and carbonate salts, in, Sandia National Laboratories: Albuquerque, New Mexico, 2012.

[8] C. Prieto, J. Gallardo-González, F.J. Ruiz-Cabañas, C. Barreneche, M. Martínez, M. Segarra, A.I. Fernández, Study of corrosion by Dynamic Gravimetric Analysis (DGA) methodology. Influence of chloride content in solar salt, Solar Energy Materials and Solar Cells, 157 (2016) 526-532.

[9] Á.G. Fernández, J.C. Gomez-Vidal, Thermophysical properties of low cost lithium nitrate salts produced in northern Chile for thermal energy storage, Renewable Energy, 101 (2017) 120-125.

[10] R.W. Bradshaw, W.M. Clift, Effect of chloride content of molten nitrate salt on corrosion of A516 carbon steel, in, Sandia National Laboratories, 2010.

[11] W.-D. Steinmann, D. Laing, R. Tamme, Development of PCM storage for process heat and power generation, Journal of Solar Energy Engineering, 131 (2009) 041009.

[12] D. Laing, T. Bauer, W.D. Steinmann, D. Lehmann, Advanced high temperature latent heat storage system - Design and test results, in: The 11th International Conference on Thermal Energy Storage - Effstock, Stockholm, Sweden, 2009.

[13] T. Bauer, D. Laing, R. Tamme, Characterization of Sodium Nitrate as Phase Change Material, International Journal of Thermophysics, 33 (2012) 91-104.

[14] D. Laing, C. Bahl, T. Bauer, D. Lehmann, W.-D. Steinmann, Thermal energy storage for direct steam generation, Solar Energy, 85 (2011) 627-633.

[15] A. Lomonaco, D. Haillot, E. Pernot, E. Franquet, J.-P. Bédécarrats, Sodium nitrate thermal behavior in latent heat thermal energy storage: A study of the impact of sodium nitrite on melting temperature and enthalpy, Solar Energy Materials and Solar Cells, 149 (2016) 81-87.

[16] R.J. Petri, T.D. Claar, L.G. Marianowski, Evaluation of molten carbonates as latent heat thermal energy storage materials, in: 14 th Intersociety Energy Conversion Conference, Boston, MA, USA, 1979.

[17] J.Q. Sun, R.Y. Zhang, Z.P. Liu, G.H. Lu, Thermal reliability test of Al-34\%Mg-6\%Zn alloy as latent heat storage material and corrosion of metal with respect to thermal cycling, Energy Conversion and Management, 48 (2007) 619-624.

[18] C.C. Leiby, T.G. Ryan, Thermo-physical properties of thermal energy storage materials Aluminum, in, 1973.

[19] Y. Jiang, Y. Sun, M. Liu, F. Bruno, S. Li, Eutectic Na2CO3-NaCl salt: A new phase change material for high temperature thermal storage, Solar Energy Materials and Solar Cells, 152 (2016) 155-160. [20] C. Edeleanu, R. Littlewood, Thermodynamics of corrosion in fused chlorides, Electrochimica Acta, 3 (1960) 195-207. 
[21] H.A.A. El-Rahman, A. Baraka, S.A.A. El-Gwad, Effect of oxide ion donors on the corrosion and dechromization of stainless steels in $\mathrm{KCl}-\mathrm{NaCl}-\mathrm{BaCl} 2$ melt, Journal of Applied Electrochemistry, 29

445 (1999) 1205-1210.

446 [22] K. Sridharan, T.R. Allen, Chapter 12 - Corrosion in Molten Salts, in: F. Lantelme, H. Groult (Eds.)

447 Molten Salts Chemistry, Elsevier, 2013.

448 [23] American Iron and Steel Institute, High temperature characteristics of stainless steel - A designers' Handbook Series No.9004, in, Nickel Development Institute. [24] L. Ye, C. Tang, Y. Chen, S. Yang, J. Yang, W. Zhang, One-step extraction of antimony from lowgrade stibnite in Sodium Carbonate - Sodium Chloride binary molten salt, Journal of Cleaner Production, 93 (2015) 134-139. [25] A. International, ASTM G1-03(2011), Standard Practice for Preparing, Cleaning, and Evaluating Corrosion Test Specimens, in, West Conshohocken, PA, 2011. [26] C.M. Kramer, Z.A. Munir, J.V. Volponi, Differential scanning calorimetry of sodium and potassium nitrates and nitrites, Thermochimica Acta, 55 (1982) 11-17. [27] A. Shukla, D. Buddhi, R.L. Sawhney, Thermal cycling test of few selected inorganic and organic phase change materials, Renewable Energy, 33 (2008) 2606-2614. [28] Z. Liu, D.D.L. Chung, Calorimetric evaluation of phase change materials for use as thermal interface materials, Thermochimica Acta, 366 (2001) 135-147. [29] L. Ye, C. Tang, Y. Chen, S. Yang, M. Tang, The thermal physical properties and stability of the eutectic composition in a Na2CO3-NaCl binary system, Thermochimica Acta, 596 (2014) 14-20. [30] T.-H. Lim, E.R. Hwang, H.Y. Ha, S.W. Nam, I.-H. Oh, S.-A. Hong, Effects of temperature and partial pressure of $\mathrm{CO}_{2} / \mathrm{O}_{2}$ on corrosion behaviour of stainless-steel in molten $\mathrm{Li} / \mathrm{Na}$ carbonate salt, Journal of Power Sources, 89 (2000) 1-6. [31] S. Frangini, Corrosion of metallic stack components in molten carbonates: Critical issues and recent findings, Journal of Power Sources, 182 (2008) 462-468.

468 [32] R.W. Bradshaw, D.H. Goods, Corrosion of alloys and metals by molten nitrates, in: C.A.C. 469 Sequeira (Ed.) High Temperature Corrosion in Molten Salts, Trans Tech Publications Ltd, 2003. 